\title{
Identification of Meat Species by Using Molecular and Spectroscopic Techniques
}

\author{
Evrim Gunes Altuntas ${ }^{1^{*}}$, Ebru Deniz ${ }^{2}$, Beycan Ayhan $^{3}$, Kezban Candogan ${ }^{2}$, \\ Duygu Ozel Demiralp ${ }^{4}$
}

${ }^{1}$ Biotechnology Institute, System Biotechnology Advanced Research Unit, Ankara University, 06100 Ankara, Turkey
${ }^{2}$ Department of Food Engineering, Faculty of Engineering, Ankara University, 06110 Ankara, Turkey
${ }^{3}$ Dişkapı Yıldırım Beyazıt Training and Research Hospital, Aziz Sancar Research Institute, 06110 Ankara, Turkey
${ }^{4}$ Department of Biomedical Engineering, Faculty of Engineering, Ankara University, O6110 Ankara, Turkey ART ICLE IN F O A B T R A T

Review Article

Received 31 October 2016 Accepted 20 December 2016

Keywords:

Meat and meat products

Meat adulteration

Identification of meat species

DNA-based methods

Spectroscopic methods

\begin{abstract}
Meat is one of the main nutrition source in the human diet with its excellent protein, vitamin and mineral contents. Despite its advantages, being high-priced makes meat products open to adulteration. Meat products are mixed food types which can contain different species of meat. However, mixing two or more types of meats is not always allowed by laws. On the other hand, replacement high quality meats with cheaper meat types are a cost lowering way for the producers. The commonly consumed meat types differ from country to country, but generally economical, ethnic and religion concerns are in the foreground. In this case, species identification techniques are gaining importance. Although some techniques depending on DNA or spectroscopy have been developed for many years, choosing the best method for species identification is still among the controversial issues today. Thus, the currently used methods and promising techniques in this area were discussed in this review.
\end{abstract}

*Corresponding Author:
E-mail: egunes@ankara.edu.tr
DOI: https://doi.org/10.24925/turjaf.v5i5.488-492.1060

\section{Introduction}

Meat is a great protein source and a basic nutritious food making valuable contribution to the human diet (Arihara, 2006; Zhang et al., 2010; Hathwar et al., 2012). In European countries beef consumption in 2012 reached 6.94 million tonnes, and it is well known that for the last 50 years beef consumption values have been roughly constant (Zhao et al., 2013). To date, although there are several meat types available for human consumption, beef, chicken and pork account for the largest share within the total meat consumption. A part of these meats can be used as fresh meat for immediate consumption while some can be processed in different ways into a wide variety of processed meat products representing a significant global market share.

Customers are gaining interest to know the origin of the foods because of quality-related reasons, health and safety reasons and concerns about animal welfare. Due to some cost and religion concerns the meat producers have to comply with some rules issued by the legal institutions (Murugaiah et al., 2014). For this reasons, meat authenticity focusing on determination of species or origin has been drawing a great attention as an emerging area of research with scientific and technological developments in this regard (Ayhan, 2013). This subject has always been in the hot topics of science, thus several techniques were developed to date (Esslinger et al., 2014). These techniques can be classified in four categories; mass spectrometry techniques, spectroscopic techniques, separation techniques such as HPLC, GC and other technologies (sensor technology, DNA technology) (Luykx et al., 2008).

Current available methods used to identify different species are electrophoresis, liquid chromatography, dot blot hybridization, randomly amplified polymorphic DNA PCR, RFLP analysis, and species-specific PCR (Aida et al., 2005; Syahariza et al., 2005; Che Man et al., 2007). However, molecular techniques are considered as reliable methods to identify meat types since there is a need to develop faster, cheaper and safe methods. Besides histological tests, immunoassays or DNA analysis, spectroscopic techniques are gaining interest due to being low cost and easily applied (Hashim et al., 2010; LermaGarcia et al., 2010; Zhang et al., 2012). The power of the spectroscopy comes from giving chance to detect or quantify physical, chemical and biological attributes of the samples based on their spectral signature, and imaging 
transforms this information into chemical maps for spatial visualization. Thus, these methods can be used to determine what attributes, how much and where they are located in the sample (Kamruzzaman et al., 2013).

Among DNA based methods, PCR has been proved to be an adequate technique for detection of small amounts of DNA, specifically amplifying a target region of template DNA in a rapid and sensitive manner (Kesmen et al., 2012). Many DNA sequences have been analysed for various animals such as fish, game species and several domestic animals. Compared to other techniques for species identification by DNA-based methods, polymerase chain reaction-restriction fragment length polymorphism (PCR-RFLP) analysis has already been successfully applied for species differentiation in heated and processed meat products like sausages (Aida et al., 2005).

It is estimated that adulteration rates of cooked meat products are higher than raw meats. Adding poultry meat to beef by mixing mechanically deboned poultry tissue with ground or comminuted mammalian products is a common way to decrease costs (Doosti et al., 2014). A new trend accepted by USA is that all food adulterations are potential food safety issues on the basis that people have limited or no knowledge of any potential food safety implications when they consume adulterated food (Zhao et al., 2014).

On the other hand, there are three main difficulties in developing authenticity methodology: first of all, a legal requirement, standard or guidance are needed for all cases, the second difficulty is finding a marker which characterizes the relavant food. The third one is the need for authentic samples available for the development and evaluation of the method (Primrose et al., 2010).

\section{DNA Based Methods to Identify the Meat Types}

Meat and meat products are very susceptible to spoilage and also expensive as compared to other food types. Therefore, their composition and quality has always been interested. When considered from industrial and marketing perspective, the major raw materials in the processing of meat appear as carcasses of beef and pork (Kartheek et al., 2011).

Among the techniques used for species identification, PCR is a DNA based technique allowing the detection of very low amounts of nucleic acid probes and the determination of their sequence via the amplification of DNA or RNA individual strains. This method has some advantages such as high sensitivity and rapid performance with high sample numbers. However, PCR technique needs resistant material and both ends of the target DNA must be known (Luykx and van Ruth, 2008). Further, some processing techniques may cause degradation on DNA which decrase the amplification rate of PCR. This seems one of the disadvantages of DNA based methods, but usually degraded DNA can give a positive result such as in the study conducted by Che Man et al. (2007). This study results showed that PCR could be performed successfully with DNA isolated from sausages which is a processed meat product.

While ostrich meat composition is similar to poultry, its sensory properties are closer to beef. So, ostrich meat can be used in meat mixtures instead of beef without labeling. In a study by Abdulmawjood et al. (2014), a sensitive and specific method was developed to identify ostrich meat in the meat mixtures by using a loopmediated isothermal amplification (LAMP) assay depending on the cytochrome $b$ gene of the mitochondrial DNA of the species Struthio camelus. LAMP technique which was combined with real time fluorometer allowed to detect about $0.01 \%$ ostrich meat products with 15 to 20 minutes sampling-to-result identification time (Abdulmawjood et al., 2014).

Pork is the most common meat type used for adulteration in foods. Che Man et al. (2007) performed a study for the aim of identification pork in some food products including sausages. Genomic DNA was extracted from food products and then subjected to species-specific PCR targeting the specific regions of the 12S rRNA gene. This technique provided excellent results to identify pork derivatives and was suggested as a reliable technique for Halal certification.

Directly DNA sequencing technique requires good quality DNA, however, denaturated DNA may lead to form false bands or ambiguous sequence results in mixed species. At this point, PCR-RPLF has several advantages such as being cost-effective, accurate detection and applicable for mixed foods containing multiple species (Murugaiah et al., 2009).

A method was developed by Aida et al. (2005) for pork and lard sample identification by using PCR of a conserved region in the mitochondrial cytochrome $b$ gene. Genomic DNA of pork and lard were extracted and subjected to PCR assay. After PCR products were cut with restriction enzyme (BsaJI), restriction fragment length polymorphisms (RPLF) was applied. The PCRRFLP technique yielded satisfactory results for identification of the pig species suggesting that the method has a potential use for Halal authentication.

In yet another aspect, identification of fraud or adulteration is significant in Muslim countries due to religious reasons. Though pork is the most widely consumed meat in the world (Murphy et al., 2014), this meat type is accepted as haram (unlawful or prohibited) meat in Islamic countries. For this aim, 224 meat products containing 68 sausages, 48 frankfurters, 55 hamburgers, 33 hams and 20 cold cut meats were obtained from different companies and markets from Iran (Doosti et al., 2014). After isolation of genomic DNA of the samples, PCR-RFLP technique was performed to detect of beef, sheep, pork, chicken, donkey and horse meats. It was reported that 6 fermented sausages, 4 frankfurters, 4 hamburgers, 2 hams and 1 cold cut meat contained haram (unlawful or prohibited) meat.

In a study conducted by Murugaiah et al. (2009), PCR-RFLP method was achieved to identify beef, pork, buffalo, quail, chicken, goat and rabbit species. PCR products were obtained from $c y t b$ gene of the meat 
materials and then AluI, BsaI, RsaI, MseI and BstUI enzymes were chosen as restriction endonucleases. Genetic differences between those six meat types could be successfully confirmed with this method and a reliable typing scheme of the species was developed.

A rapid TaqMan-based duplex real-time PCR method was performed by Kesmen et al. (2014). This method based on simultaneous amplification of fragments of the mitochondrial ND2 and ND5 genes and used for the identification and quantification of pork and donkey meats in raw/cooked donkey-beef and pork-beef mixtures. As a result of this study $0.001 \%$ of the meat species in raw and oven-cooked mixtures and $0.01 \%$ of the meat species in autoclaved meat mixtures could be detected successfully.

The methods depending on DNA and ELISA (enzyme linked immunosorbent assay) are certainly most specific and sensitive techniques for food components detection, but these techniques are complex to perform when compared to chromatographic and electrophoretic assays (Murugaiah et al., 2009; Boyaci et al., 2014). Even so, USDA (United States Department of Agriculture, Food Safety and Inspection Service, Office of Public Health and Science USA) has a laboratory guide in order to use ELISA for identification of animal species in cooked and canned meat and poultry. Insomuch that a kit depend on ELISA for specification of meat types was developed by USDA and commercially used. ELISA or PCR methods are known as complex techniques, but it is a good way to simplize them by compacting in a kit. This is more applicable for ELISA and will not need a qualified staff.

RAPD (Random Amplified Polymorphic DNA) is a very fast, easy to perform, and does not require expensive equipment method. In this method, PCR allow the examination of genomic variation without prior knowledge of DNA sequences (Huang et al., 2003). RAPD PCR can be used to identify the meat species and produce good fingerprints from processed products in which DNA has been only slightly degraded, such as smoked or salted products (Martinez and Yman, 1998).

\section{Spectroscopic Methods to Identify Meat Types}

Spectroscopic methods, including Fourier Transform Infrared Spectroscopy (FT-IR) have been taken into consideration due to the need for new and rapid analytical methods in the field of food adulteration. These methods are generally based on transmittance or reflectance readings, and they require none or very little sample pretreatment (Reis et al., 2013). Infrared (IR) spectroscopy as a well accepted analytical technique because it is environment-friendly and does not need complicated sample preparation procedure (Al-Jowder et al., 1997; Hashim et al., 2010; Liu et al., 2012; Liu et al., 2013).

The meatball is a popular meat product consumed in many countries. For some economical reasons, substitution of beef with pork meat is an encountered problem for people and organizations as well. A study was applied FT-IR spectroscopy in combination with chemometrics of partial least square (PLS) and principal component analysis (PCA) for determination of pork fat (lard) in meatball (Kurniawati et al., 2014). In fact, FT-IR is a good option to use for quantitative analysis of fats and oils (Che Man et al., 2005; Kuligowski et al., 2008; Jaiswal et al., 2015). In the study performed by Kurniawati et al. (2014), the wavenumber region of 1018$1284 \mathrm{~cm}^{-1}$ was determined as the quantitively identification point of lard in meatball. Besides this, 1200$1000 \mathrm{~cm}^{-1}$ region was reported for the classification of lard and beef fat in meatball broth. In a similar study conducted by Rohman et al. (2011), Kurniawati et al. (2014) used FT-IR spectroscopy and then partial least square (PLS) in order to show pork adulteration in meatball. The spectral bands related to pork fat (PF), beef fat $(\mathrm{BF})$, and their mixtures in meatball formulation were scanned and identified by spectroscopically representative to pure PF and BF. Fingerprint regions of 1200-1000 $\mathrm{cm}^{-1}$ were selected for quantitative analysis and FT-IR predicted values in PLS calibration model was $\mathrm{y}=$ $0.999 x+0.004$. This model was subsequently applied for the prediction of independent samples using laboratory made meatball samples containing the mixtures of BF, thus FT-IR spectroscopy was indicated for the detection and quantification of pork in beef meatball formulation for Halal verification purposes.

Horsemeat is not included in food chain in many countries because it is deemed unfit for human consumption. In Europe, although horsemeat utilization in meat products is forbidden, this meat was detected in a number of beef burgers. Furthermore, in UK, Food Standards Agency (FSA) found horsemeat in some beef products and removed these products from supermarket shelves (Boyaci et al., 2014; Jakes et al., 2015).

A reliable distinguishing protocol for beef and horsemeat types was suggested by Jakes et al. (2015). The researchers performed $60 \mathrm{MHz}{ }^{1} \mathrm{H}$ NMR spectroscopy depending on the comparison of triglyceride signatures of the meats. Peak integrations were found sufficient to understand meat types that 76 extractions for fresh beef and 62 extractions for horsemeat were calculated.

A new approach in determination of beef adulteration with horsemeat was developed by Boyaci et al. (2014). Raman spectra was performed to collect data and then PCA (principal component analysis) was used as chemometric calculation. Pure fat sample extracted from 49 beef and horsemeat samples were analyzed with this technique and it was reported that classification of the meats was achieved in a short analysis time and without time-consuming sample preparation techniques.

Biological materials are problematic in the mid-IR region since they are generally opaque, highly-scattering and contain significant amounts of water. At this point attenuated total reflection (ATR) sample accessories have been applied for such materials successfully (Downey, 1998). Zhao et al. (2014) examined adulteration in fresh and frozen beefburger by producing authentic and offaladulterated beefburger samples in laboratory media. Midinfrared ATR spectroscopy and multivariate data analysis showed that $100 \%$ correct classification accuracies were 
obtained separately for fresh and frozen-then-thawed material.

Minced meat production causes to differ morphological characteristics of muscles, so this form of meat is open to cheat. Turkey meat is one of the candidate to be selected for adulteration due to its low cost compared to beef. Spectroscopic techniques (UV-visible, near-infrared and mid-infrared) coupled with chemometric techniques to detect minced beef adulteration. For this purpose 154 mixtures of minced beef adulteration with turkey meat in $5-50 \%$ proportions were used and the data were analyzed. Principal Component Analysis (PCA), Linear Discriminant Analysis (LDA), and Partial Least Squares (PLS) regression were performed to interpret the results. It was reported that the best results were obtained with NIR and MIR spectroscopy, whereas the UV-vis results were less satisfactory (Alamprese et al., 2013).

Similarly, minced lamb could be mixed with cheaper meat species. After minced pork in the range $2-40 \%$ (w/w) at approximately $2 \%$ increments were added to minced lamb, a rapid analytical technique based on nearinfrared (NIR) hyperspectral imaging was used to detect adulteration in minced lamb by Kamruzzaman et al. (2013). Four important wavelengths $(940,1067,1144$ and $1217 \mathrm{~nm}$ ) were selected to estimate adulteration by using weighted regression coefficients $(\mathrm{Bw})$ and a multiple linear regression (MLR) model. The developed model allowed to detect adulteration in minced lamb samples.

Rat meat adulteration in meatballs was searched by using FT-IR combined with PLS (Rahmania et al., 2015) . For quantitative analysis, the relationship between actual values and FT-IR predicted values of rat meat is described by the equation of $y=0.9417 x+2.8410$ with coefficient of determination of 0.993 and root mean square error of calibration of $1.79 \%$. In addition, PCA could be successfully used for the classification of rat and beef meatball.

\section{Conclusions}

There is a great concern by consumers for good quality products of which origin is clear as well. The legal authorities need to find reliable ways to analyze the products and control the manufacturers by laws. Both the control mechanisms of the government and the producers need simply, low-cost and applicable methods in order to sustain autocontrol. To date DNA based methods have always been in demand due to being dependable and certain. However, these techniques are too costly and need qualified-staff. At this point, the researchers oriented to spectroscopic techniques such as NIR, MIR, FT-IR. If these techniques can be combined with chemometric analyses the results could be satisfactory for the identification origins of the foods. Indeed, species identification method should be chosen according to the purpose. In routine analyses while spectroscopic techniques appear to be advantageous, in lab scale, DNA based methods might provide more reliable results.

\section{References}

Abdulmawjood A, Grabowski N, Fohler S, Kittler S, Nagengast H, Klein G. 2014. Development of loop-mediated isothermal amplification (LAMP) assay for rapid and sensitive identification of ostrich meat, PLOS ONE, 9(6), e100717. doi:10.1371/journal.pone.0100717.

Aida AA, Che Man YB, Wong CMVL, Raha AR, Son R. 2005. Analysis of raw meats and fats of pigs using polymerase chain reaction for Halal authentication, Meat Sci, 69: 47-52.

Al-Jowder O, Kemsley EK, Wilson RH. 1997. Mid-infrared spectroscopy and authenticity problems in selected meats: a feasibility study, Food Chem, 59(2): 195-201.

Alamprese C, Casale M, Sinelli N, Lanterı, S, Casıraghı, E. 2013. Detection of minced beef adulteration with turkey meat by UVevis, NIR and MIR spectroscopy. LWT-Food Sci. Technol. 53: $225-232$.

Arihara K. 2006. Strategies for designing novel functional meat products, Meat Sci, 74(1): 219-229.

Ayhan B. 2013. Spectrometric and spectroscopic investigation of multiple Mmyeloma, PhD Thesis submitted to Ankara University, Biotechnology Institute, Ankara, Turkey.

Boyacı IH, Temiz HT, Uysal RS, Velioğlu HM, Yadegari RJ, Rishkan MM. 2014. A novel method for discrimination of beef and horsemeat using Raman spectroscopy, Food Chem, 148: 37 41.

Che Man YB, Syahariza ZA, Mirghani MES, Jinap S, Bakar J. 2005. Analysis of potential lard adulteration in chocolate and chocolate products using Fourier transform infrared spectroscopy. Food Chem, 90: 815-819.

Che Man YB, Aida AA, Raha AR, Son R. 2007. Identification of pork derivatives in food products by species-specific polymerase chain reaction (PCR) for Halal verification, Food Control, 18: 885-889.

Doosti A, Dehkordi PG, Rahimi E. 2014. Molecular assay to fraud identification of meat products, J Food Sci Technol, 51(1): 148152.

Downey G. 1998. Food and food ingredient authentication by midinfrared spectroscopy and Chemometrics, Trends Anal Chem, 17(7): 418-424.

Esslinger S, Riedl J, Fauhl-Hassek C. 2014. Potential and limitations of non-targeted fingerprinting for authentication of food in official control, Food Res Int, 60: 189-204.

Hashim D, Man YC, Norakasha R, Shuhaimi M, Salmah Y, Syahariza Z. 2010. Potential use of Fourier transform infrared spectroscopy for differentiation of bovine and porcine gelatins, Food Chem, 118(3): 856-860.

Hathwar SC, Rai AK, Modi VK, Narayan B. 2012. Characteristics and consumer acceptance of healthier meat and meat product formulations-a review, J Food Sci Technol, 49(6): 653-664.

Huang MC, Horng YM, Huang HL, Sin YL, Chen MJ. 2003. RAPD Fingerprinting for the Species Identification of Animals. AsianAust J Anim Sci, 16(10): 1406-1410.

Jaiswal P, Jha SN, Borah A, Gautam A, Grewal MK, Jindal G. 2015. Detection and quantification of soymilk in cow-buffalo milk using Attenuated Total Reflectance Fourier Transform Infrared spectroscopy (ATR-FTIR), Food Chem, 168: 41-47.

Jakes W, Gerdova A, Defernez M, Watson AD, McCallum C, Limer E, Coloquhoun IJ, Williamson DC, Kemsley EK. 2015.Authentication of beef versus horse meat using $60 \mathrm{MHz}$ 1H NMR spectroscopy, Food Chem, 175: 1-9.

Kamruzzaman M, Sun DW, Elmasry G, Allen P. 2013. Fast detection and visualization of minced lamb meat adulteration using NIR hyperspectral imaging and multivariate image analysis, Talanta, 103: 130-136.

Kartheek M, Anton Smith A, Kottai Muthu A, Manavalan R. 2011. Determination of Adulterants in Food: A Review, J Chem Pharm Res, 3(2): 629-636.

Kesmen Z, Yetiman AE, Sahin F, Yetim H. 2012. Detection of chicken and turkey meat in meat mixtures by using real-time PCR assays, J Food Sci, 77(2): 167-173. 
Kesmen Z, Gulluce A, Yilmaz MT, Yetiman AE, Yetim H. 2014. Taqman-based duplex real-time polymerase chain reaction approach for the detection and quantification of donkey and pork adulterations in raw and heat-processed meats, Int J Food Prop, 17(3): 629-638.

Kuligowski J, Quintas G, Garrigues S, De La Guardia M. 2008. Determination of lecithin and soybean oil in dietary supplements using partial least squares-Fourier transform infrared spectroscopy, Talanta, 77: 229-234.

Kurniawati E, Rohman A, Triyana K. 2014. Analysis of lard in meatball broth using Fourier transform infrared spectroscopy and chemometrics, Meat Sci, 96: 94-98.

Lerma-Garcia M, Ramis-Ramos G, Herrero-Martinez J, SimoAlfonso E. 2010. Authentication of extra virgin olive oils by Fourier-transform infrared spectroscopy, Food Chem, 118(1): 78-83.

Liu J, Chen J, Dong N, Ming J, Zhao G. 2012. Determination of degree of substitution of carboxymethyl starch by Fourier transform mid-infrared spectroscopy coupled with partial least squares, Food Chem, 132: 2224-2230.

Liu J, Wen Y, Dong N, Lai C, Zhao G. 2013. Authentication of lotus root powder adulterated with potato starch and/or sweet potato starch using fourier transform mid infrared spectroscopy, Food Chem, 141: 3103-3109.

Luykx DMAM, Van Ruth SM. 2008. An overview of analytical methods for determining the geographical origin of food products, Food Chem, 107: 897-911.

Martinez I, Yman IM. 1998. Species identification in meat products by RAPD analysis. Food Res Int, 31 (6-7): 459-466.

Murugaiah C, Noor ZM, Mastakim M, Bilung LM, Selamat J, Radu S. 2009. Meat species identification and Halal authentication analysis using mitochondrial DNA, Meat Sci, 83: 57-61.

Murphy KJ, Parker B, Dyer KA, Davis CR, Coates AM, Buckley JD, Howe PRC. 2014. A comparison of regular consumption of fresh lean pork, beef and chicken on body composition: a randomized cross-over trial, Nutrients, 6: 682-696.
Primrose S, Woolfec M, Rollinson S. 2010. Food forensics: methods for determining the authenticity of foodstuffs, Trends Food Sci Technol, 21: 582-590.

Rahmania H, Sudjadi, Rohman A. 2015. The employment of FT-IR spectroscopy in combination with chemometrics for analysis of rat meat in meatball formulation, Meat Sci, 100: 301-305.

Reis N, Franca AS, Oliveira LS. 2013. Discrimination between roasted coffee, roasted corn and coffee husks by Diffuse Reflectance Infrared Fourier Transform Spectroscopy, LWTFood Sci Technol, 50: 715-722.

Rohman A, Sismindari, Erwanto Y, Che Man YB. 2011. Analysis of pork adulteration in beef meatball using Fourier transform infrared (FT-IR) spectroscopy, Meat Sci, 88: 91-95.

Syahariza ZA, Che Man YB, Selamat J, Bakar J. 2005. Detection of lard adulteration in cake formulation by Fourier transform infrared (FT-IR) spectroscopy, Food Chem, 92: 365-371.

USDA Labotatory Guide Book MLG 17.02: ELISA for identification of animal species in cooked and canned meat and poultry.

Zhao M, O'Donnel CP, Downey G. 2013. Detection of offal adulteration in beefburgers using near infrared reflectance spectroscopy and multivariate modelling, J Near Infrared Spec, 21(4): 237-248.

Zhao M, Downey G, O’Donnell CP. 2014. Detection of adulteration in fresh and frozen beefburger products by beef offal using midinfrared ATR spectroscopy and multivariate data analysis, Meat Sci, 96: 1003-1011.

Zhang Q, Liu C, Sun Z, Hu X, Shen Q, Wu J. 2012. Authentication of edible vegetable oils adulterated with used frying oil by Fourier Transform Infrared Spectroscopy, Food Chem, 132(3): 1607-1613.

Zhang W, Xiao S, Samaraweera H, Lee EJ, Ahn DU. 2010. Improving functional value of meat products, Meat Sci, 86: 1531. 